\title{
Dynamics and conceptual model of the Rossena castle landslide (Northern Apennines, Italy)
}

\author{
A. Chelli ${ }^{1}$, G. Mandrone ${ }^{2}$, A. Ruffini ${ }^{3}$, and G. Truffelli ${ }^{4}$ \\ ${ }^{1}$ Dept. of Earth Scienze, University of Parma, Parco Area delle Scienze, 157/a, 43100 Parma, Italy \\ ${ }^{2}$ Dept. of Earth Scienze, University of Torino, Via valperga Caluso 35, 10125 Torino, Italy \\ ${ }^{3}$ Geologic consultant, Via Volturno 128, 43100 Parma, Italy \\ ${ }^{4}$ Emilia Romagna Region, Provincial Technical Service of Reggio, Italy
}

Received: 19 July 2005 - Revised: 2 September 2005 - Accepted: 9 September 2005 - Published: 10 November 2005

Part of Special Issue "Documentation and monitoring of landslides and debris flows for mathematical modelling and design of mitigation measures"

\begin{abstract}
In the Northern Apennines there are many historical villages and castles, which are of great value and represent a cultural heritage of great importance. Their presence within a territory greatly affected by landslide hazards creates, in many circumstances, the need to solve problems of land management and to act for the preservation of historical monuments.
\end{abstract}

This paper describe an interesting landslide, failed during the night of 28 February 2004, that involved the village of Rossena: the failure damaged the village (Fig. 1), the road and the fields down to the stream but, fortunately, the castle just upslope the village was not involved at all.

The 10th century massive castle of Rossena stands on the top of a cliff at about $500 \mathrm{~m}$ a.s.l., on the border between the provinces of Parma and Reggio Emilia, and it is surrounded by a small ancient village. The castle of Rossena is the best preserved stronghold of the Longobard times, enlarged and reinforced in the tenth century and partially rebuilt by Bonifacio, the father of Matilda of Canossa (the Vice-Queen of Italy and probably the most important woman in the Middle Ages) as a defensive structure guarding the Enza Valley. In addition, at Conossa, very close to Rossena, there was the meeting between Pope Gregory VII and the Emperor of Germany Henry IV, during the historical event known as "fight for the investitures". For these reasons, the area of Rossena is one of the most relevant from a historical point of view in the entire western part of the Emilia Romagna Region and it also has a high value as a geosite (Coratza et al., 2004).

Correspondence to: G. Mandrone

(giuseppe.mandrone@unito.it)

\section{Introduction}

The territory of the Emilia Romagna Region (Northern Italy) pertaining to the Northern Apennines involves a large number of landslides of different types and sizes: the latest inventory (Regione Emilia Romagna, 1999) reports more than 30000 landslides, interesting about $20 \%$ of the mountainous and hilly terrain. The large number of landslides is linked, mainly, to the geological features of the Northern Apennines, a fold and thrust belt which started to develop in the Late Cretaceous (Bettelli and De Nardo, 2001). The complex tectonic history of the chain determined the superimposition of many stratigraphic units containing heterogeneous and/or chaotic rocks characterized by poor geomechanical properties which cause the strong tendency for slope movement (Bertolini and Pellegrini, 2001).

The aim of the study is to find an engineering-geological model of the gravitative phenomena that involve the Rossena Castle and the surrounding area, especially those parts subjected to recent reactivations. Thanks to these studies, it will be possible to adequately project the mitigation and remedial action plans. Further studies will deal with the reconstruction of the condition for the failure and with the numerical modeling of the landslide.

\section{General framework}

In the Rossena area two main rock units outcrop (Fig. 2): mainly dismembered and tectonically fatigued clay and shale formations and a more or less fractured and weathered ophilolitic sequence (Papani et al., 2002).

The chaotic clay complex is made up of at least three different rock types with similar geotechnical behavior (Mandrone, 2004): a sequence made of rock blocks in a pelitic matrix (limestone in shales), a scaly varicolored clay formation 


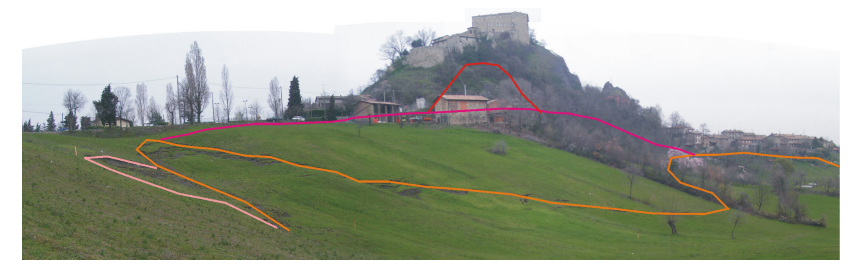

Fig. 1. Panoramic view of the higher part of the Rossena Landslide. Keys: orange line $=$ main body $($ rotational), purple line $=$ earth slide (translational), red line $=$ rock slide, pink line $=$ secondary landslide.

and a mélange of clay and pieces of rocks of different nature (blocks of basalt, limestone and slices of flysch ranging from a few centimeters to many meters).

The ophiolitic masses are dismembered allochthonous bodies packaged within the chaotic complex. In the area these masses are of different sizes (from a few meters to many hundreds of meters) made up, especially, of massive basalts, serpentine and pillow lavas; it is also very common to find large outcrops of breccias too, sometimes polygenic and more or less cemented. They outcrop in cliffs that show a high degree of joints and faults, according to main tectonic stress fields. Frequently fractures are very open or infilled with clay and pieces of rocks fallen inside.

The morphology of the area is characterized by the ophiolitic masses that stand out on the ground and are evident because the erosive processes removed the soft surrounding pelitic rocks. The most prominent body is the Rossena cliff, where the Rossena castle stands. A scree slope surrounds the entire cliff bottom. It is made mainly by clasts of centimetric size with a silty-clayey reddish matrix. The slope on the north-eastern side of the cliff develops downwards for about $1 \mathrm{~km}$ reaching the small stream at its foot. Between the stream and the toe of the landslide, in the southernmost part of it, there is a small alluvial deposit.

The slope shows an irregular profile characterized by concave areas and scarps highlighting the fact that the morphology is mainly due to landslides and slope instability processes. Where the pelitic rocks outcrop, linear erosive processes, like rill erosion, caused the development of badlands.

The slope instability in this area is usually triggered by rainfalls, especially in autumn and spring, but in this case the landslide occurred in February, when there were $30-40 \mathrm{~cm}$ of snow cover on the Rossena area. It is interesting that the failure happened one day after the only day in which the temperature did not exceeded $0^{\circ} \mathrm{C}$ : so, probably, the snow melting and the following re-freezing that can be regarded, at least, as one of the main triggering factors. Moreover, the previous year (2003) was particularly dry and in $N$. Italy there was a deficit of about $20-50 \%$ of rainfall, especially in the spring and summer. This fact induced an extensive superficial cracking of the mainly clayey formations so the rains of the following seasons could reach, more than usual, the deeper parts of the slopes. Therefore, the melting of the snow of February 2004 added water in a situation in which probably the groundwater level were already higher than usual,

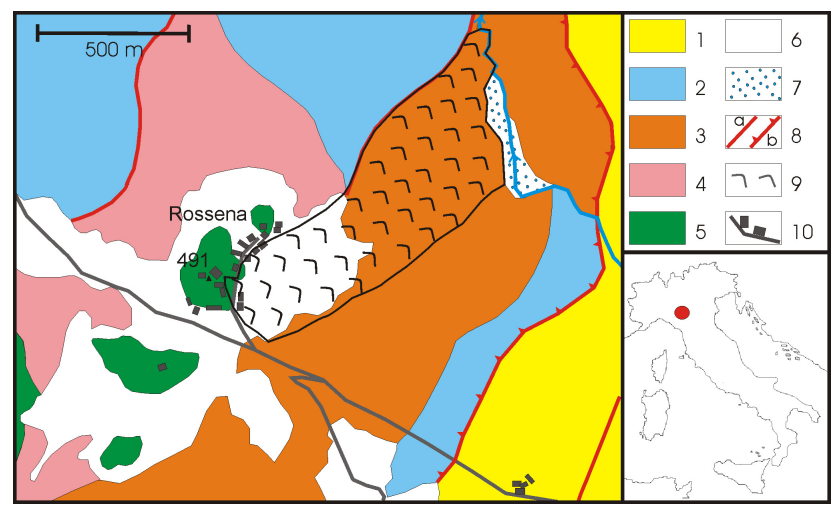

Fig. 2. Location of the Rossena landslide and geological sketch of the surrounding area. Keys: 1) clayey breccias, 2) limestone in shales, 3) varicolored shales, 4) tectonic mélange (clay with blocks), 5) ophiolites, 6) slope deposits, 7) alluvial deposit, 8) faults (a) and trust (b), 9) Rossena landslide, 10) roads and buildings.

causing an abrupt increasing in pore pressure and the failure of the following day.

\section{Geologic and geomorphologic evidence}

A detailed geomorphologic and geologic survey allowed us distinguishing the different landslides that shape the northeastern slope of the Rossena area (Fig. 3). The Global Positioning System (GPS) device was employed to map the boundaries of the landslide bodies and to place the morphologic indicators of the different movements. In particular, it was possible to distinguish the portions of the landslides where there are spreading movements from the others where compressive ones appear, therefore it was possible to map the different landslide bodies and, mainly, solve the complex situation that characterized the middle-lower portion of the slope.

From the top to the bottom of the slope different types of landslides were identified, with each one involving different parts of the slope (sectors A, B, C, D in Fig. 4).

The cliff of the Rossena castle (sector A) is crossed by many families of fractures, which cut the basaltic mass in different directions. They allowed the disjointing of the mass in huge blocks that underwent differential movement in the eastern part of the cliff. During the 28 February event some blocks collapsed, with about $1 \mathrm{~m}$ of vertical offset (Fig. 5), just below the wall of the old building, while topplings involved the outer blocks (Fig. 6). Small rock falls and debris flows occurred respectively on the front of the cliff and in the covers that surrounds it, made of debris in a clayey matrix. A rotational-translational landslide involved the slope below the cliff, developing in the oldest part of the village. Several fractures, with offset between 1 and $2 \mathrm{~m}$, widened in the ground and many small landslides occurred just after the main event, enlarging the crown and the flanks of the main landslide, and contributing to damaging the village. 


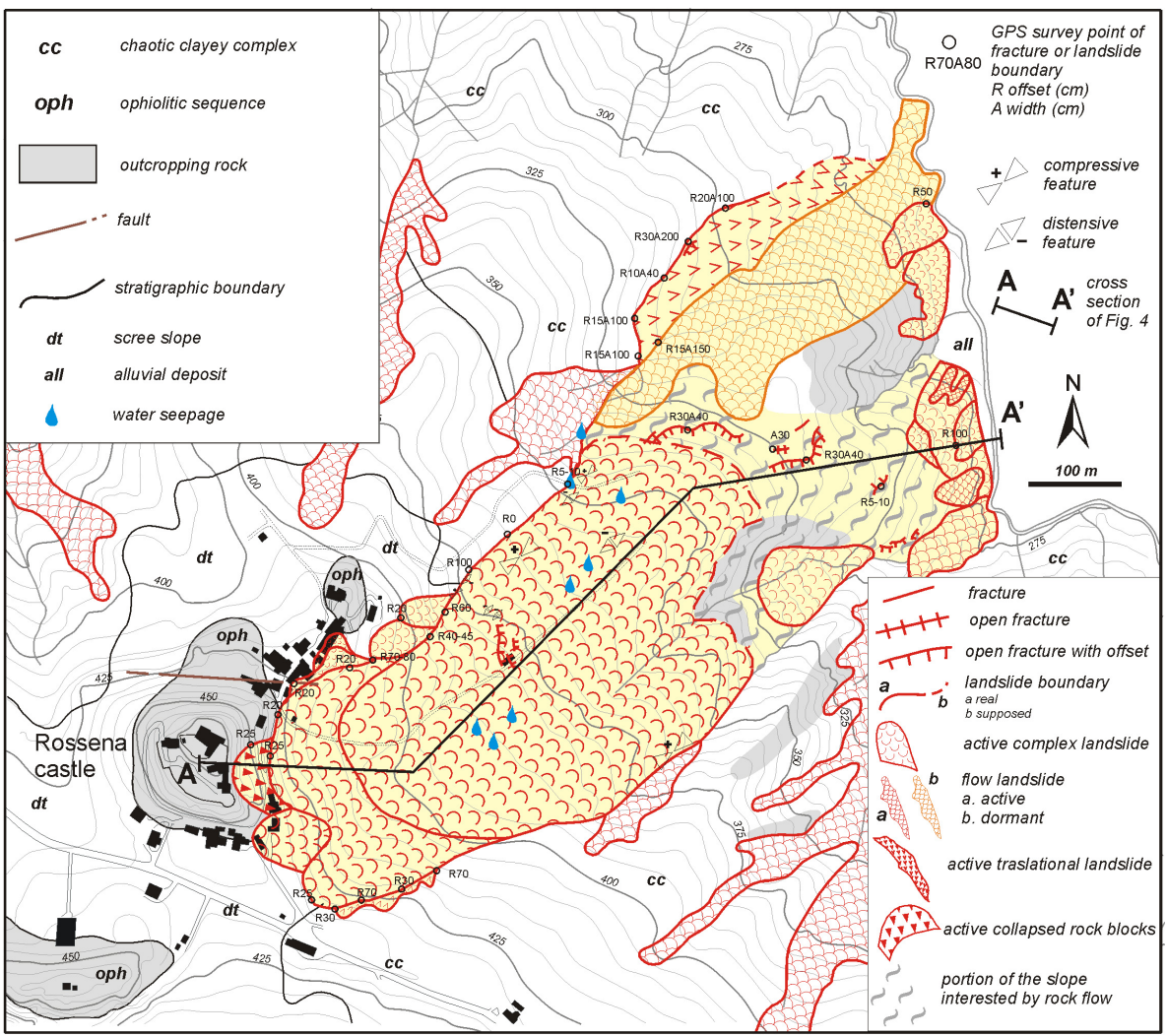

Fig. 3. Geological-geomorphologic sketch of the Rossena Landslide (highlighted in pale yellow) and surrounding area.

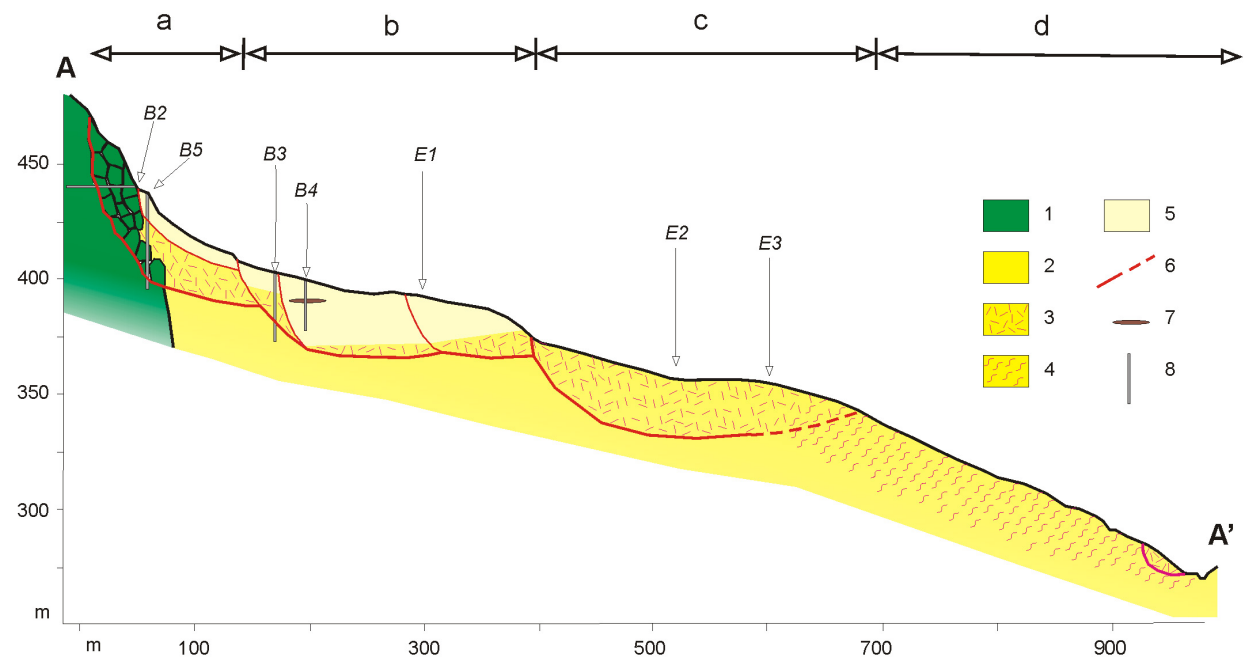

Fig. 4. Cross section of the Rossena Landslide. Keys: 1) ophiolites, 2) varicoloured shales, 3) idem, involved in the landslide, 4) idem, involved in the rock creep, 5) slope deposits, 6) slip surface, 7) organic layer of 10000 y b.p., 8) boreholes (B) and vertical electrical soundings (E). Letters at the top of the picture show the four morphological units in which the landslide can be divided.

The top of sector B is at about $390 \mathrm{~m}$ a.s.l., where there is a gentle concave area that is the morphological expression of the head of a rotational landslide. Different springs appear in this area: they likely mark the boundary between an upper layer made by material deriving from the wasting of the basaltic cliff, in which a water seepage can develop, and a lower one made up by a mainly clay-rich material, mainly impermeable, deriving from the varicolored clay formation (both levels are involved in the landslide). The type of movement changes in the middle-lower part of the landslide, turning into a flow type and, on the whole, this part of the landslide may be classified as a complex phenomenon (rotational slide-flow). 


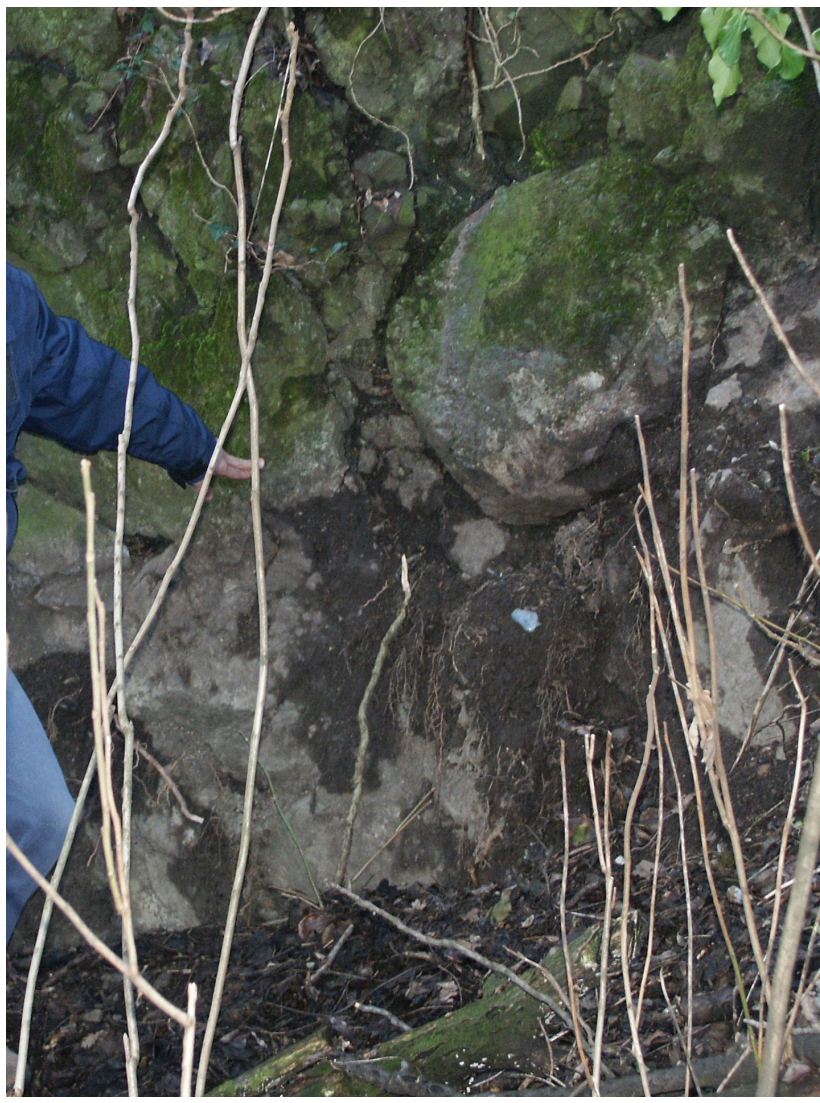

Fig. 5. Vertical offset between stable basaltic cliff and dismembered blocks.

Sector C is characterized by another concave surface where some other springs appear. On the right side of the surface, there is a very steep scarp where varicolored clay outcrops. Downslope, many series of fractures, some of them showing decimetric offset, appear in the ground, developing from the center of the slope towards northeast. On the basis of their distribution, the fractures seem to be the expression of an initial failure of this part of the slope rather than a welldefined landslide body.

An extended well-stratified and preserved outcrop of the varicolored clay formation is in correspondence of the foot of the slope (sector D). It seems to contrast the development of the landslide, playing the role of a buttress. Actually, the landslide divides into two tongues in correspondence of the change in acclivity: the first one, on the right of the outcrop, is affected by many fractures and secondary landslides, whilst the second one, on the opposite side of the varicolored clay outcrop, reaches the torrent at the foot of the slope. The features of this last part of the landslide allow to state that it is an earth-flow, but no evidence of recent movement was found. This fact proves that this specific part of the landslide was not involved in the event of 2004 and it is, at present, in a dormant state of activity. Moreover, some small landslides, mainly of complex (rotational slide-flow) type, and debris-flow affected the foot. They developed concomitantly

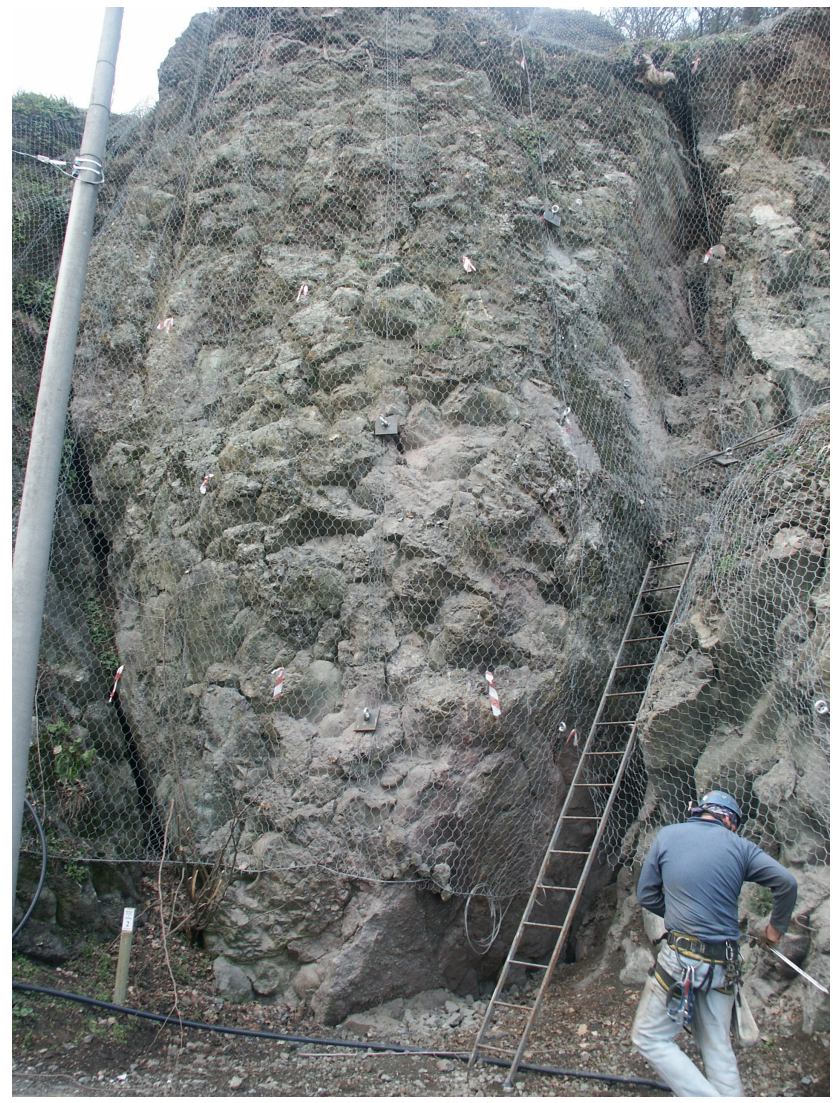

Fig. 6. Unstable basaltic block at the base of the cliff.

with the last event or during the days immediately after the initial movement in 2004. The presence of alluvial deposit between the landslides and the stream prevented the undermining from the latter, during the event. This fact suggests that the cause, at least for the right part, was the failure of the rock mass at the back, which produced a widespread destabilization at the foot of the main landslide body.

Outside the landslide area, on the left side of it, a fracture crosses the slope starting from 315 and reaching $290 \mathrm{~m}$ a.s.l., where it disappears. It developed concomitantly with the February 2004 event and shows variable width, from 40 to $200 \mathrm{~cm}$, and variable vertical offset of some decimeters. It is the morphological expression of a translational landslide.

\section{Subsurface investigations}

Direct and indirect methods of investigation, planned and controlled by the Emilia Romagna Region - Provincial Technical Service of Reggio Emilia, were used to investigate the subsurface characteristics of the Rossena landslide in order to solve some of the uncertainties remaining after the geomorphologic mapping (Fig. 7). Investigations focused especially on the upper part of the main body, near the road, the castle and the village. In detail, the program of investigations included: a) 9 borings ( 6 core drillings) were extended deep enough to identify materials that were subject to 


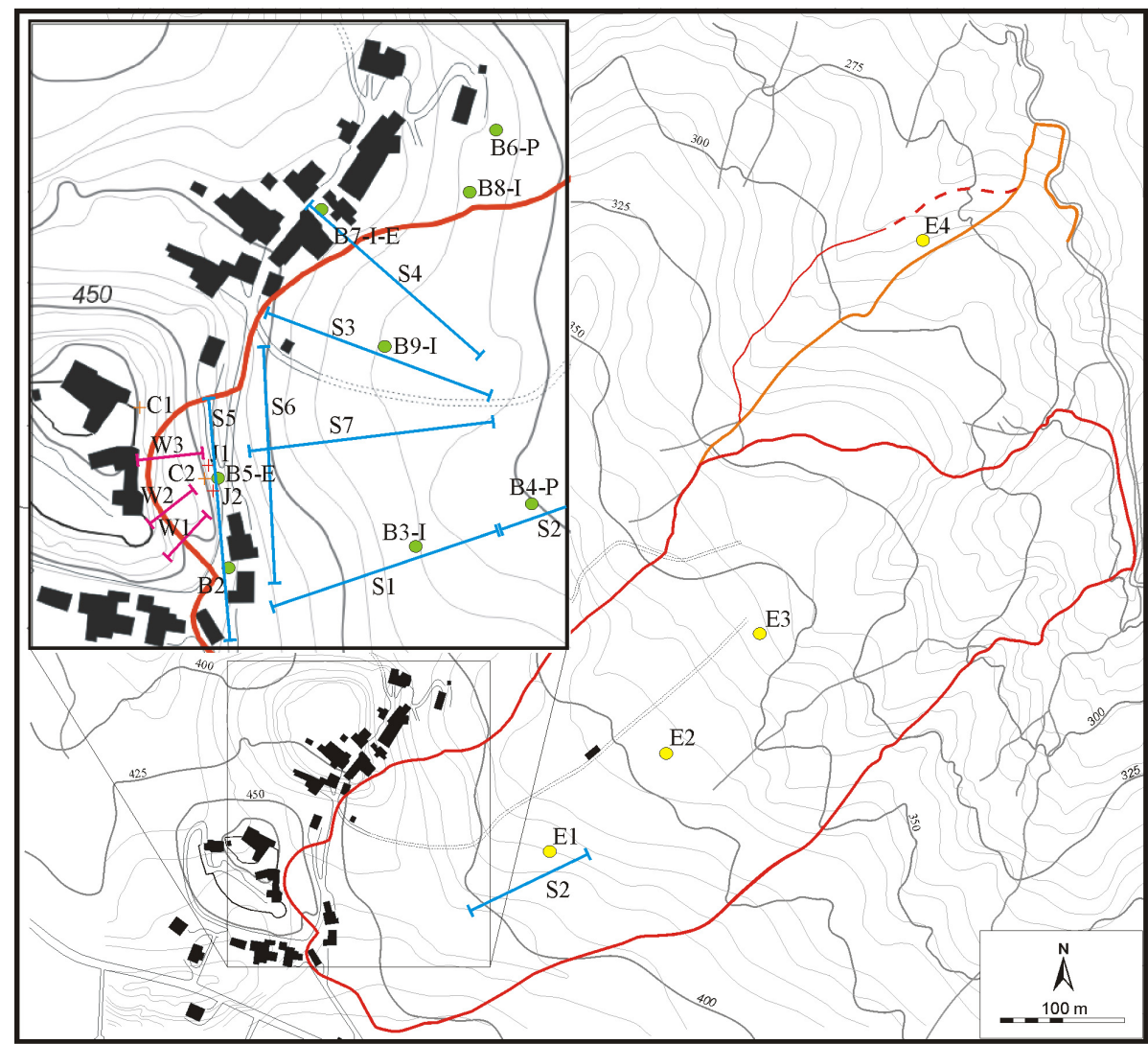

Fig. 7. Location of the subsurface observations, field instrumentations and monitoring system. Keys: $\mathrm{B}=$ boring (used as $\mathrm{I}=\mathrm{inclinometer,} \mathrm{E}$ $=$ extensometer, $\mathrm{P}=$ piezometer), $\mathrm{S}=$ seismic survey, $\mathrm{E}=$ electrical survey, $\mathrm{C}=$ clinometer (tiltimeter), $\mathrm{W}=$ wire extensometer, $\mathrm{J}=$ jointmeter.

movements and they allowed to clearly identify underlying stable materials and to acquire groundwater data, b) 7 seismic surveys (tomography), using refraction methods, were used to determine a three dimensional view of the geometry of the landslide, and c) 4 electrical surveys (vertical sounding) were used to identify the sliding surface, especially in the lower part of the slope.

As regards the cliff, boreholes show that the ophiolitic rock mass consists mainly of pillow basalt affected by many cataclastic zones (at least, 3 in $20 \mathrm{~m}$ in the sub-horizontal drilling B5) in which tectonic breccias are very common. Borehole B3 is interesting: it highlights that the external part of the basaltic cliff is fractured in big blocks and the joints between them can be very open (up to decimeters). They likely conduct a huge quantity of water at the base of the cliff. The ophiolitic body is embedded within the varicolored scaly clay and the passage between these two lithologies is characterized by a very weathered and jointed rock mass so that, especially the more external parts can be considered as made up of many big blocks that locally can move each other.

Seismic tomography allows determining the subsurface geometry of the landslide bodies, showing multiple landslide units linking each other both crosswise (S4-S5) and lengthwise (S1-S2-S3-S6-S7) the unstable slope and some big blocks of high velocity material probably fallen or toppled from the ophiolitic cliff, then wrapped up in a colluvial clay matrix. The average thickness of the landslide is between 20 and $30 \mathrm{~m}$, but locally the sliding surface can reach more than $40 \mathrm{~m}$.

Vertical electrical soundings, unfortunately, show no large contrasts in resistivity so it is difficult to define sharp boundaries. They agree with other data in the higher part of the slope (E1), while other soundings (E2-E3) are characterized only by clear superficial reflectors $(4-5 \mathrm{~m})$. E4 investigates the lateral enlargement at the bottom of the main landslide, between 315-290 $\mathrm{m}$ a.s.l., and show a sharp change in resistivity at about $20 \mathrm{~m}$ in depth.

\section{Laboratory tests}

Grain size analyses and Atterberg limits of five samples from boreholes B3 and B4 show that they can all be classified as organic clay generally with a very high degree of plasticity (except sample B4 $-23.8 \mathrm{~m}$ ). Moreover, these analyses show that the base of the landslide (sample B3-11 m), made up of varicolored clay, is a weak rock that, if weathered, becomes soil containing over $60 \%$ clay; the colluvium (B3 -3 m) connected with this bedrock is slightly coarser, showing about the same amount of clay, a little less silt and a little more sand and gravel. The material of the main landslide body is composed of well-graded grains, a little finer in the first $15 \mathrm{~m}$ 
(B4 $-10.5 \mathrm{~m}$ ) and a little coarser at the bottom (gravels reach about $50 \%$ in the $\mathrm{B} 4-23.8 \mathrm{~m})$.

Between these two levels, in borehole B4, a layer containing organic matter was found; a sample of it was subjected to radiocarbon dating and gave an age of $8960 \pm 60{ }^{14} \mathrm{C}$ yr B.P. (Beta-197895); moreover, the fabric of this level is very close to that of the colluvium mantling the slope.

\section{Monitoring system}

First, a simple system of monitoring (3 wire extensometers and 1 inclinometer) was built up immediately after the event in February 2004 (Fig. 7). It was progressively substituted, in the following months, by a more complex one in which tiltmeters (2), jointmeters (2), inclinometers (2), incremental extensometers ( 1 vertical and 1 horizontal) and piezometers (2) play an important role. Most of this equipment are fitted with data loggers, collecting many measurements per day.

The first system served to identify the rates of movement and to determine approximately the depths and shapes of landslide masses, so that the second one could be adequately planned in terms of selection of the specific types of instruments that best suited the problem, definition of locations and depths of the instrumentation and, finally, the development of data acquisition techniques. The wire crack meters obtained the results to show that the cliff was substantially stable. Some movements were recorded contemporarily by the three instruments in the following months but their entity was small.

The second system of monitoring, still in use, is very differentiated and involves a large part of the upper portion of the landslide. The best results were obtained with classic inclinometers: they show that the movements continued for months but with very small displacements (no more than 2$3 \mathrm{~cm}$ ). Vertical and horizontal incremental extensometers are coherent with this information, like clinometers and jointmeters. On the other hand, electrical piezometers show that in the landslide body water levels are quite regular, due to the low hydraulic conductivity of these terrains.

\section{Conceptual model}

The slope of Rossena shows many types of landslides, with different styles, distributions and states of activity, contributing to the evolution of a complex picture. The entire planning of the field investigations allowed us to interpret the situation of the slope.

The main movement is the complex landslide (max. movements $\approx 2 \mathrm{~m}$ ) starting at about $390 \mathrm{~m}$ a.s.l. (sector $\mathrm{B}$ ). It is of rotational-translational type and its surface of movement reaches, in correspondence of the head forming a large flat area, almost $40 \mathrm{~m}$ of depth. The last part of the landslide masks, with superficial flows (max. $10 \mathrm{~m}$ thick), the lower phenomenon whose presence suggested by the flat area at $360 \mathrm{~m}$ a.s.1. This latter section (sector $\mathrm{C}$ ) is a rototranslational slide too that involved, as a whole, a large por- tion of the bedrock. This configuration is verified by the state of preservation of the rocks outcropping in the scarp below the back tilted surface, which appears worse if compared with that of the same rocks at the foot of the slope.

The landslides of sectors $\mathrm{B}$ and $\mathrm{C}$ can be considered as the "engine" of the whole instability picture. At present the landslides of sector B show the most evident signals of movement and they tend to develop at the expense of the lower ones. Indeed, sectors C and, mainly, D underwent, during the 28 February event, an initial failure rather than a true sliding movement; this breakdown, as testified by the offsets in the concave areas, likely accounted for many fractures which appeared in the ground and was due to the "push" from the back-standing complex landslide that progressively involves the downslope landslide body. For this reason, the geometrical relationships between the landslides of sectors $\mathrm{B}$ and $\mathrm{C}$ are unclear and it is difficult to definitely state which was the first one to move.

The main instability in sectors B-C determined the mass movements in both the highest and the lowest part of the slope. The huge blocks (sector A), in which the outer part of the Rossena cliff is disjointed experienced vertical displacements and, locally, topplings. It also determined the development of relatively small superficial landslides at the foot of the slope (sector D), which probably contributes to the widespread instability, generating a self-feeding mechanism which progressively led to the evolution of the slope. It is possible that sector $\mathrm{D}$ is affected by a slow movement that involves some tens of meters of bedrock: it can be probably regarded as a bedrock creep or a rock flow (Varnes, 1978; Clerici et al., 2002).

This complex situation is the result of an evolution starting about more than 10000 years ago. In fact, the texture of the layer dated with radiocarbon method accounts for the presence of different landslide events, at least two, separated by a colluvial cover in which organic matter was accumulated. Moreover, the texture of the deeper landslide deposit shows the presence of a coarser grain size, connected with intense physical weathering of the cliff, probably due to different and more severe climatic conditions. Indeed, late Pleistocene landslide events were found in the Northern Apennines, interesting phenomena which are still active (Tellini and Chelli, 2003). As a matter of fact, according to historical research, the Rossena landslide was already triggered on 13 March 1832 by a 7-8 MCS degree earthquake, with epicenter some $20 \mathrm{~km}$ away (Colla, 1832). This quake induced the breaking up part of the rock cliff causing rock falls and cracks in the ground.

\section{Conclusions}

The Rossena landslide can be described as a composite and complex landslide, multiple in its central part (sectors BC), confined and, as a whole, enlarging (Cruden and Varnes, 1996). The total length of the landslide is about $1000 \mathrm{~m}$, its mean width about $250 \mathrm{~m}$, while its depth spans between 20 
and $30 \mathrm{~m}$. It covers the area of approx. $300000 \mathrm{~m}^{2}$, with a volume of approximately 7 million $\mathrm{m}^{3}$.

The failure in the event of February 2004 was abrupt, reaching a maximum displacement of about $1-2 \mathrm{~m}$. In the following weeks, many small lateral landslides enlarged the main body and for several months the landslide underwent very slow and negligible movements.

The historical relevance of the Rossena Castle requires particular attention in the project of the mitigation and remedial measures. Indeed, just after the event of 2004, the Emilia Romagna Region (Provincial Technical Service of Reggio Emilia) organized some stabilization (e.g. unstable rock block and debris removal, rock bolts and superficial drainage), and protection measures (catch fences) in order to mitigate the risk around the cliff.

Later, on the basis of the investigations and monitoring, in agreement with the National Commission of High Hydrogeological Risks, a hypothesis of remedial action plans was formulated, aiming to achieve stabilization and mitigation of the total risks affecting the Castle and the village of Rossena. The stabilization program includes structural measures (walls, anchors, piles) and deep drainages (vertical wells connected by subhorizontal gravity drains).

At the end, the natural hydrography will be restored with the help of surface drains along the landslide and the surrounding area. Moreover, after the structural remedies, the monitoring system will remain partially operative and provide information on the functionality of the works.

Acknowledgements. Many thanks to C. Tellini (University of Parma) and G. Wieczorek (U.S.G.S.) for a "friendly" technical review of the paper. Personal contributions to this paper included: A. Ruffini conducted the GPS field surveys, G. Truffelli operated the monitoring systems and remedial action plans, while A. Chelli and G. Mandrone are mainly responsible for other paragraphs. Founds: Fil UniPr 2004 (Head S. Perego), 60\% UniTo (Head M. Fornaro).

Edited by: M. Arattano

Reviewed by: G. Bottino

\section{References}

Bettelli, G. and De Nardo, M.T.: Geological outlines of the Emilia Apennines (Italy) and introduction to the rock units cropping out in the areas of the landslides reactivated in the 1994-1999 period, Quad. Geol. Appl., 8, 1-26, 2001.

Bertolini, G. and Pellegrini, M.: The landslides of the Emilia Apennines (Northern Italy) with references to those which resumed activity in the 1994-1999 period and required Civil Protection interventions, Quad. Geol. Appl., 8, 27-74, 2001.

Clerici, A., Mandrone, G., Tellini, C., and Vescovi, P.: The geomorphological and kinematic evolution of the Anzola Landslide (Northern Apennines, Italy), in: Landslide - Proc. 1st Europen Conf. on Landslides, Prague, Czech Republic, 24-26 June 2002, edited by: Rybar, J., Stemberk, J., and Wagner, P., Swets \& Zeitlinger, Lisse, 143-148, 2002.

Colla, A.: Relazione del terremoto che ha danneggiato Parma e luoghi vicini nel mese di marzo 1832, Antologia, 46, 137, 75-78, 1832.

Coratza, P., Tosatti, G., Pellegrini, M., Piacente, S., and Vernia, L.: Geodiversity in the landscape of Emilia-Romagna (Northern Italy): geosites in the Apennines between Modena and Reggio Emilia, field trip guide book, 32nd Int. Geol. Congr., Florence, 20-28 August, 24, 2004.

Cruden, D. M. and Varnes, D. J.: Landslide types and processes, in: Landslides: investigation and mitigation, Special Report 247, edited by: Turner, A. K. and Schuster, R. L., Transportation Research Board, National Research Council, Washington, 36-75, 1996.

Mandrone, G.: Assessing the geomechanical features to some of the most common heterogeneous rock units in the northern Apennine, Quad. Geol. Appl., 11, 1-14, 2004.

Papani, G., De Nardo, M. T., Bettelli, G., Rio, D., Tellini, C., and Vernia, L.: Carta geologica d'Italia alla scala 1:50000 - Foglio 218 Castelnuovo ne' Monti, Selca, Firenze, 2002.

Tellini, C. and Chelli, A.: Ancient and recent landslide occurrences in the Emilia Apennines (Northern Apennines, Italy), in: Proc Workshop on Geomorphological sensitivity and system response, Camerino-Modena Apennines (IT), edited by: Castaldini, D., Gentili, B., Materazzi, M., and Pambianchi, G., 105114, 2003.

Regione Emilia Romagna: I numeri delle frane, edited by: Garberi, M. L., Palumbo, A., and Pizzaiolo, M., Grafiche Damiani, Bologna, 1999.

Varnes, D. J.: Slope movement types and processes, in: Landslides: analysis and control, Special Report 176, edited by: Schuster, R. L. and Krizek, R. J., Transportation Research Board, National Research Council, Washington, 11-33, 1978. 